\title{
Fear and empathy in international relations: Diplomacy, cyber engagement and Australian foreign policy
}

\author{
Luigi Di Martino ${ }^{1,2}$
}

Revised: 20 August 2020 / Accepted: 1 April 2021

(c) The Author(s), under exclusive licence to Springer Nature Limited 2021

\begin{abstract}
Emotions in international relations, as in human relations, are invisible but leave traces in the policy articulation. Such traces can reveal how emotional interpretations of the environment in which national states operate shape and frame certain policy and strategic choices. Drawing on the concept of the "institutionalisation of empathy and fear" developed by Crawford (Int Theory 6(3):535-557, 2014), I first operationalise and then apply this concept to the Australian foreign policy. This framework is applied to the analysis of the foreign policy documents and strategies published by the Australian government in the last decade. In particular, I focus on Australia's foreign policy articulation and interpretation of the internet and digital technologies. New, pressing problems are emerging in the digital environment due to a range of cybersecurity threats, including an increase in the frequency of automated accounts and the dissemination of fake news and digital propaganda. From perceiving the internet as a communication platform that allows for listening to and dialogue with foreign publics, Australian foreign policy is increasingly framing the internet as strategic infrastructure that requires defending and guarding. The attention is, thus, moving towards short-term 'defensive' goals - as a result of a higher perceived fear of the latest evolution in the geopolitical context. The shift in Australian foreign policy indicates a form of institutionalisation of fear in response to the challenges emerging from the digital environment. I conclude by arguing that a more belligerent international environment highlights the tension between national interest—which evolves and changes due to political shifts and contextual elements - and the understanding of public diplomacy engagement as mutual understanding and mutual influence.
\end{abstract}

Keywords Public diplomacy $\cdot$ Cyber diplomacy $\cdot$ Digital diplomacy $\cdot$ Engagement $\cdot$ Australia

\section{Introduction}

A nation state's perception of the threats and possibilities in the international environment is visible in the way that it frames priorities across policy documents. In the postCold War international environment, concepts such as "soft power" have demonstrated the importance of attraction rather than military force-the so-called hard power (Nye 2004). The emphasis on soft power has been fuelled by the emergence of social media in international communication. Scholars working on the study of public diplomacy have

Luigi Di Martino

L.DiMartino@westernsydney.edu.au

1 Institute for Culture and Society, Western Sydney University, Sydney, Australia

2 Present Address: Institute for Culture and Society, Western Sydney University, Building EM, Parramatta campus, Locked Bag 1797, Penrith, NSW 2751, Australia highlighted the importance of building long-term confidence and a focus on attraction, rather than coercion, as the currency of contemporary international relations (Zaharna 2010; Fisher 2013; Hocking 2008; Melissen 2005).

New, pressing problems, such as the increase in the frequency of automated voices and the dissemination of fake news and propaganda in digital communication, have challenged the emphasis on "soft" or communication-focused approaches to international relations. Emerging uses of social media platforms as communication weapons rather than bridges are posing serious questions for future public diplomacy practices. Internet governance and cybersecurity, rather than communication outcomes, are increasingly becoming predominant foreign policy concerns for nation states. We are witnessing a shift from the emphasis on the need for more public diplomacy to an endorsement by many nation states of more "defensive" or "militarised" approaches to digital technologies in international relations. 
In this paper, I argue that such a shift can be analysed by applying and operationalising the concept of the "institutionalisation of fear and empathy" developed by Crawford (2014). She argues that "where empathy is low and societies may be locked in cycles of antipathy and aggression, fear and opportunities to increase it are institutionalized in military budgets, arms race dynamics, and cross-border skirmishes" (547). Fear (or its opposite emotion, empathy)

may be institutionalized in physical structures (e.g. fences, fallout shelters) the adoption of technologies (e.g. X-rays of baggage at airports), and development of rules of procedure and military doctrines (e.g. preemption and preventive war) that are intended to reduce the subjective sense of threat and fear but which may simultaneously and inadvertently heighten conditions that produce more fear (549).

In order to operationalize and apply Crawford's work relating to the institutionalisation of emotions in the field of international relations, I focus on the case of the Australian foreign policy articulation in relation to digital technologies. I study the institutionalisation of fear in public diplomacy policy articulation and the role played by emotions in international relations by assessing programmes and institutions of Australian public diplomacy, with a particular focus on Australian government's strategic understanding of the internet in foreign policy. I critically examine recent Australian foreign policy strategies and argue that the Australian government, in contrast to what is suggested in much of the academic literature on public diplomacy, has moved towards a more 'militarised' understanding of the internet (e.g. focusing on issues such as cybersecurity rather than on the opportunities to engage with foreign publics online).

In the sections below, I examine both the practices and the academic literature on public diplomacy and the initial interpretation of digital platforms as communication tools. I begin by exploring some of challenges that have emerged in the last few years in relation to the internet: the discussion around digital propaganda and "fake news", cybersecurity concerns due to recent cyberattacks and the consequent reinterpretation of cyberspace as a competitive environment that requires more defensive approaches. This is in contrast to how much of the literature on public diplomacy frames the internet and digital technologies as a source of new opportunities for diplomats-compared with traditional mass media communication - for dialogue with international publics. I then propose a typology of the different terms that have been recently coined or repurposed in academic literature to describe the recent, more "militarised" use of digital technologies in international relations. This discussion is followed by a description of how I methodologically operationalise the institutionalisation of fear and empathy. I then apply this methodology in the analysis of the shift in the Australian foreign policy articulation in relation to digital technologies. I argue that the shift in Australian foreign policy indicates a form of institutionalisation of fear in response to the challenges emerging in response to the digital environment.

The significance of this study stems both from the approach and from the findings of the analysis of the case study. Emotions in international relations are a central but understudied driver of foreign policy despite some notable exceptions. These include Graham (2014) who has focused on the role of emotions in influence and persuasion and Duncombe (2019) who has studied the emotional dynamics of social media in diplomacy. Nevertheless, it remains unclear whether and how emotions in international relations play an important role in strategy and policy implementation. In this paper, I argue that, as in human relations, emotions in international relations are invisible but leave traces in policy articulation. Such traces can reveal important signals about governments' perception of the environment in which they operate and, in particular, the emotional policy response to dominant perceived threats in the workings of relations between countries.

\section{Internet and diplomacy}

Developments in the public uses of digital communication technologies like the internet, mobile phones, and social media have introduced both optimism and scepticism about new forms of democracy, participation and transparency. Such technologies have greatly impacted upon international affairs for at least three important reasons: first, they are popular, second, they are widely accessible, and third, they allow for vertical and many-to-many communication.

Diplomacy has always dealt with changes and technological transformations as part of the endless evolution in international relations. Aeroplanes, radio and the telegraph, as well as social media today, have all brought about temporal acceleration and changes in diplomatic practices. Kurbalija (2013), for example, has described parallels between the introduction of the telegraph and the internet in diplomacy. In both cases, debates have emerged regarding the strategic importance of communication infrastructures and their supposed neutrality. The initial inexperience at using either the telegraph or the internet produced "techno-suspicion" and anxieties, "confusion and misunderstandings" among diplomats.

\section{Digital technologies and diplomatic practices}

Diplomatic practices, along with several other governmental activities, have been altered by the internet in two key ways. First, the internet has changed what diplomats do to 
engage with publics. Second is the ways in which it has changed the identity of actors who either influence or who are engaged with diplomacy. Just as the telegraph's introduction in the late nineteenth century was a not-entirely-welcomed transformation in the communication infrastructure among diplomats (Fong 2010), twenty-first century social media platforms have similarly created anxiety in diplomatic circles. For example, when these platforms were introduced in the US State Department, several questions and problems emerged: "Can diplomats blog? Twitter? Should comments be allowed? Should they be filtered? Who can engage? Where? For what purpose?" (Graffy cited in Richter 2016, p. 105).

With the introduction of the internet in public diplomacy - and social media in particular-scholars have begun to consider digital technology as a factor that has empowered new actors on the international stage, resulting in calls for a dialogic model of communication. In his call for a "real-time diplomacy" after the "Arab Spring" or the "Arab Awakening”, Philip Seib (2012, p. 1) argued that "individual citizens (have) become intellectually and politically empowered" and that "they use social media tools to form communities of interest that enhance political activism". ${ }^{1}$

In 2010, the US State Department under Secretary of State Hillary Clinton decided to bring "diplomacy into the digital age" (Lichtenstein 2010, para. 5) with a policy statement titled "21st Century Statecraft" (US Department of State n.d.). According to Jared Cohen and Alec Ross, who at that time were working for the State Department, this plan "represent[ed] a shift in form and in strategy—a way to amplify traditional diplomatic efforts, develop tech-based policy solutions and encourage cyberactivism" (Lichtenstein 2010, para. 5). American influence had thus to be exercised "on a more multilateral basis, and doing so under the frame of global citizenship, instead of quoting 'America's Values", (Forenstein 2011). According to Clinton (2010), the technological tools should be made as widely available as possible, since "the internet is a network that magnifies the power and potential of all others. And that is why we believe it is critical that its users are assured certain basic freedoms. Freedom of expression is first among them" (para. 14).

However, concerns started to emerge in the public and academic debate in relation to the assumption that digital technologies inherently produce positive changes in international relations. For example, Clinton's plan was criticised for promoting the continued close association between the State Department and Silicon Valley, such "that repressive regimes now see Google, Facebook and Twitter as tentacles of American foreign policy's reach, putting all users of those internet tools under suspicion" (Morozov, cited in Barton

\footnotetext{
${ }^{1}$ See also Seib (2016, pp. 26-30) on "The Empowered Public".
}

2012, para. 9). In addition, the policy became linked to emerging widespread concerns about surveillance and digital forms of control over freedom of expression, highlighted in the seminal book The Net Delusion by Evgeny Morozov (2011). A Belarusian writer and researcher, Morozov is one of the most well-known and prolific critics of cyber-utopianism, and in particular has criticised claims that citizens' will be empowered by the kinds of digital technologies featured in American "21st Century Statecraft" policy. In The Net Delusion Morozov (2011) highlights the contradictions in the idea of internet freedom espoused by the Clinton policy. While the internet was fuelling the democratising aspirations of Western governments and mainstream news media during the Iranian protests around the presidential elections of 2009, the Iranian government was effectively using the internet as a surveillance tool to monitor and suppress any opposition. This political repression was conducted using the same so-called "liberation technologies" as the opposition were, with the Iranian government identifying and tracking down activists by inspecting photos and videos of the protests that were posted by protestors to social media.

In 2013, following on from debates that surrounded Clinton's policy announcement regarding the paradox of freedom on the internet, The Guardian published a series of classified documents leaked by a system analyst employed by the US National Security Agency, Edward Snowden. The leak provided evidence that the US National Security Agency was indiscriminately intercepting internet and phone conversations of citizens around the world, a fact that ran counter to the US's officially declared support for internet freedom and that undermined the validity of its policies to advance internet freedom globally (Greenwald 2013). Following subsequent revelations that internet 'dragnet' surveillance was also being carried out by the Five Eyes, ${ }^{2}$ this leak increased global concerns about mass surveillance on social media, especially that which was conducted by the American government (Landau 2014).

These concerns have fostered the debate about the public sphere and the democratic role of the internet and social media. The promotion of social media as a tool for freedom and liberation by the US State Department has been directly countered and contradicted by evidence of the use of social media as a repressive surveillance tool by states including the US. The governmental use of the internet for surveillance has challenged the idea of social media as an intrinsically empowering dialogic tool (Barash et al. 2018).

Meanwhile, new questions about the quality, accuracy and accessibility of news on social media have emerged. Pariser (2011) warned how algorithms and internet engines

\footnotetext{
2 An intelligence alliance constituted by the United States, United Kingdom, Australia, Canada, New Zealand.
} 
create a "unique universe of information"- - he called this a "filter bubble" - by selectively guessing what information a user would like to see based on data collected from that user (e.g. location, past clicks, search history). The US presidential elections in 2016 and the election of the President of the United States, Donald Trump, generated further public and academic debate about misinformation on social media. Filter bubbles, along with the spreading of 'fake news' (a journalistic term used to describe the proliferation of misinformation on social media) assisted, according to some (e.g. Solon 2016), in Trump's election.

Nowadays, large numbers of online messages can be sent immediately with limited resources, in contrast to the expensive and centralised technologies of mass media (Tufekci 2018). Social bots - created to produce automatically generated messages on social media- "are considered to be capable of massively distributing propaganda in social and online media, and their application is even suspected to be partly responsible for recent election results" (Grimme et al. 2017, p. 279).

More recent events have also revealed that a private company, Cambridge Analytica, was able to breach Facebook policies and illegitimately acquire personally identifiable information, then used for political and electoral purposes (Solon 2016). This has raised questions about the use of big data for malicious purposes. Such concerns have emerged from practices that have shaped and informed the academic debate around the role of digital technology in international relations.

\section{Scholarly debate about digital technologies in international relations}

At this point, it is worth briefly exploring some of the main evolutions in the analysis provided by scholars in the last two decades in relation to the introduction of the internet in international relations. The list below is not intended to be exhaustive but rather provides a brief summary of some of key terminologies used in the academic literature surrounding digital technologies and international relations. Six main terms have emerged to describe the evolution in the use and interpretation of digital technologies in diplomacy: the new public diplomacy, digital diplomacy, cyber diplomacy, the dark side of diplomacy, new forms of propaganda and information warfare.

1. The new public diplomacy. Across the academic literature, it is generally recognised that digital tools-and social media in particular-are now part of everyday diplomatic activities. The earlier academic focus on what diplomacy should or ought to be with the introduction of digital technologies and the creation of new networked publics (Grant 2004; Westcott 2008; Heine and
Turcotte 2012; Graffy 2009; Seib 2012) has since moved to emphasise digital media as an integral component of the toolset that diplomats can deploy (Trent 2016; Hocking and Melissen 2015; Sotiriu 2015; Riordan 2016b). Most recently, the literature is moving toward the investigation of what public diplomacy can achieve through digital media.

The number of heads of state, ministers, ambassadors and embassies using social media accounts is ever increasing, creating new and still unpredictable transformations in diplomacy. The necessity to create a "permanent cadre of digital professionals who can drive digital diplomacy" is now a priority for many leading governments in the development of soft power strategies, such as the U.K. (Fletcher 2016, p. 10).

To mark these changes in diplomacy practices, several new terms have been coined by scholars with varying degrees of success: "virtual diplomacy" (Smith 2010; Brown and Studemeister 2001), "cyber diplomacy" (Potter 2002), "media diplomacy" (Gilboa 1998), "democratisation of diplomacy" (Grant 2004), "digital diplomacy" (Dizard 2001; Sandre 2015; Bjola and Holmes 2015) and "public diplomacy 2.0" (Glassman 2008; Cull 2011). Across all of these terms there is general agreement about the transformations that the new digital communication technologies have brought to diplomatic practices and especially to public diplomacy.

A certain degree of popularity has been achieved by the term "new public diplomacy" coined by Jan Melissen (2005). Melissen argues that the way public diplomacy was conducted during the War on Terror caused "the perceived need for updated public diplomacy practices" (Melissen 2011, p. 9). The new public diplomacy was "generally based on a more liberal view of international relations and a reaction to the United States' approach, which was dominated by security concerns and corporate practices" (9). In particular, Melissen criticises the fact that public diplomacy was mainly conceived by governments as a one-way communication approach to foreign publics, that could not work in the new networked international environment that saw a growth of non-state actors, civil society movements and the rise of "new media", although still in their germinal stage in 2005 (Melissen 2005).

2. Digital diplomacy. While the term "new public diplomacy" reflects broader transformations in diplomacy, "digital diplomacy" is emerging in the literature as the term that embraces technological changes in diplomacy. In particular, digital diplomacy focuses on the use of social media in diplomacy. Manor (2016, pp. 28-34) identifies digital diplomacy studies published in the last decade that are predominantly aimed at evaluating the social media accounts of foreign affairs ministers. Those 
that study digital diplomacy, according to Manor, have also recognised the need for new strategies to react to terrorists' use of social media (Al-Qaida in particular), to address new forms of citizen participation online and the new communication environment shaped by digital technologies (6-7).

The evaluation of collaboration, dialogue, two-way forms of communication and engagement has been a central focus in many of these studies (Hocking and Melissen 2015; Bjola 2015). The introduction of social media in public diplomacy has, indeed, fuelled a focus on the interactive dimension of communications, especially in academia (Zaharna 2010; Fisher 2013; Hocking 2008, Melissen 2005). As foundational tools of digital diplomacy, digital platforms seem to have provided the opportunity (and sometimes created the necessity) for diplomats to put into practice what was only theorised by the "new public diplomacy" as result of "the shifting power balances in the international system induced by digital technology" (Bjola 2016, p. 298).

3. Cyber diplomacy. Along with the emerging challenges brought about by the controversial use of digital technologies explored in the previous section, Riordan (2016a) has, more recently, stressed the renewed importance of pursuing "diplomatic strategies" in response to the challenges signalled by the internet. In his recent book, he highlights "the importance of the diplomatic approach to reduce tensions and negotiate norms of behaviour" (Riordan 2019, p. 15). This is a call for more diplomacy in cyberspace. By acting more diplomatically, state and non-state actors can better deal with and negotiate the current challenges emerging from digital technologies.

4. The dark side of diplomacy. As Riordan has called for more diplomacy in cyberspace, other scholars have offered their expertise in order to suggest communication strategies to counteract the use of "influence campaigns" by foreign powers used "to exploit societal vulnerabilities to achieve their goals without military force" (Pamment et al. 2018, p. 7). This has been defined as the "dark side of digital diplomacy" (Bjola and Pamment 2018), which is to say "the use of digital diplomacy techniques for nefarious purposes" (p. 2). In this case, the term "digital diplomacy" is used in a neutral way as a set of tools that can be used both for promoting a more "pluralistic and democratic global society" as well as for creating divisions and tensions. This might push governments to rethink information containment strategies in the digital age (Bjola and Pamment 2016).

5. Propaganda. The term "propaganda", which was thought to be exclusively reliant on mass media technologies, is now regaining attention from scholars. For example, the Oxford Internet Institute launched The computational propaganda project in 2016 that aims to address the rise of new forms of propaganda on digital media (see also Bradshaw and Howard 2018). The recently published SAGE Handbook of Propaganda (Baines, O'Shaughnessy, and Snow 2019) also indicates a renewed interest in propaganda studies.

6. Information warfare. In addition to this terminology emerging from scholars who have been working on public diplomacy, there is also an increased interest in social media and cyberspace by scholars working in military science, strategic and defence study. In these fields, there is a limited but emerging interest in forms of information and social media warfare. "The Internet-Erbschloe (2017, p. 2) argues-has enabled these factions to intentionally inflict harm on each other without guns and often without face-to-face confrontation". Clearly, social media was once primarily considered as tool for "soft power" and public diplomacy but is increasingly gaining attention from other governmental departments such as defence and home affairs. This is a consequence of a more militarised use and understanding of digital communication platforms and digital technologies in general—what I will highlight below as a sign and institutionalisation of fear.

Despite the fact that attention on the containment of propaganda and malicious activities in cyberspace is growing in academic scholarship, the question of how governments are reacting to these new challenges remains largely understudied. This paper aims to help fill this gap by exploring the Australian foreign policy articulation in relation to the internet. The distinction between the internet as a communication tool and the internet as strategic infrastructure is pivotal to understanding the evolution of the Australian foreign policy articulation that I describe below.

\section{Methodology}

In this paper, I address the following research questions:

1. How can we operationalise the "institutionalisation of empathy and fear" in the analysis of foreign policy documents?

2. How have the Australian DFAT's (Department of Foreign Affairs and Trade) strategies in relation to the internet evolved over time?

3. What are the possible implications of foreign policy moved by "fear" rather than "empathy"?

In order to analyse the evolution of Australia's digital strategy, I examine four strategic documents produced by the Australian government that span the years of 2014 to 2017: the Public Diplomacy Strategy 2014-2016 (2014), 
the Digital Media Strategy 2016-2018 (2016), the Foreign Policy White Paper (2017) and Australia's International Cyber Engagement Strategy (2017). These documents reflect how the Australian government interprets the role of digital technologies in foreign policy. Responses to these documents by journalists, commentators and academics constitute the foundations and boundaries of current debates and are included in this analysis.

I use a qualitative and interpretative, problem-focused approach developed by Bacchi (2009). Founded in the idea that "policies [...] constitute (or give a shape to) "problems"" this approach focuses on how policy statements "contain implicit representations of the problem" (Bacchi 2009, 1) and requires that the researcher challenges the assumptions that lie beneath this "problem representation" (xii). Translating this into the specific case study at hand, I qualitatively coded the above-mentioned texts that exemplify how the DFAT and the Australian government define problems relating to digital technologies. This includes how "the problem" of the internet is defined in policy documents; and how such definitions inform and shape the direction of Australian foreign policy.

The "institutionalisation of fear and empathy" is operationalised by assessing the interpretation of digital technologies in the selected policy documents. As Crawford (2014, p. 547) argues, "[...] emotions and beliefs structure the organization of knowledge (e.g. intelligence gathering and threat assessment) and the development of standard operating procedures and routines for handling challenges". In this sense, references to digital technologies as communication enablers are considered a sign of openness to online foreign publics and thus the manifestation of an empathy-seeking act. When governments recognise digital technologies as enablers, they actively create communication spaces in which dialogic engagement with publics take place and they demonstrate a willingness to listen to publics (Di Martino 2020b). In this case, the internet is considered a communication platform that supports the creation of conditions for an international environment in which exchange of ideas and negotiation, even with antagonistic publics, is made possible and considered as a positive policy outcome. This is also much in line with what the literature on public diplomacy has focused on relating to the possibilities for dialogic forms of communication brought about by social media as previously discussed.

By contrast, manifestations of fear are represented by an interpretation of the internet as strategic infrastructure accompanied by a more militarised understanding of digital technologies. Here the focus is on the threats coming from malicious state and non-state actors operating on digital infrastructures rather than on the possibilities and the affordances of the internet and social media platforms to engage dialogically. The growing emphasis on these threats in policy documents is considered a sign of increasing fear perceived by state actors which is then translated into policy documents.

In the following sections, I first discuss the initial understanding of digital platforms as a communication tool, as highlighted by the Public diplomacy strategy (2014) and the Digital Media Strategy (2016). I then move my analysis to most recent policy documents-namely the Foreign Policy White Paper and the Australia's International Cyber Engagement Strategy.

\section{Australian public diplomacy: digital platforms as communication tools}

The focus on digital engagement by the Australian government is a relatively recent move. In the past decade, the Australian government has worked in different directions to build a coherent public diplomacy strategy. In particular, between 2014 and 2016, the DFAT shifted from a focus on advocacy programmes, to cultural and educational exchanges, to a focus on digital engagement. The academic attention on Australian public diplomacy has also grown, and the area can no longer be considered "terra nullius", ${ }^{3}$ as Chitty (2008, p. 314) argued in his discussion of the Senate Committee's report, Australia's Public Diplomacy: Building Our Image (2007).

In 2014, DFAT published its first public diplomacy strategy for the triennium 2014-2016 (DFAT 2014). While the strategy has been amended several times since publication, with minor readjustments regarding Australia's international role and priorities, ${ }^{4}$ its core points remained unchanged in the most recent version of May 2016, the version which will be highlighted here.

The strategy focused on "economic diplomacy" and "Australia's high levels of ethnic diversity and social harmony and our commitment to democracy, rule of law, human rights and freedom of speech, cultural diversity, gender equality, respect for people with disabilities and respect for Indigenous cultures" (3). It also reaffirmed the importance of engagement with the Indo-Pacific region, continuing the Australian commitment to the region. ${ }^{5}$ But little attention was paid to digital media.

Cave (2015a, b) encouraged the Australian government to "catch up" with the rest of the world. Despite the growing number of social media accounts, she noted that "Australia's

\footnotetext{
3 This a Latin expression that means "nobody's land".

${ }^{4}$ For example, the part addressing Australia's commitments as host country for the G20 2014 has been amended.

5 The strategy aims to achieve these goals through cultural diplomacy, media engagement, sports diplomacy, science diplomacy, the New Colombo Plan, aid programmes, diaspora communities and investment in public diplomacy content.
} 
digital diplomacy is stuck in broadcast mode, rarely progressing beyond posting official releases" on the DFAT's social media accounts.

This changed, at least at a strategic level, with the launch of the DFAT's Digital Media Strategy published in December of 2016 (DFAT 2016). With its new digital strategy, the Australian government included digital media as part of its overall diplomatic strategy. The main goal of the three-year digital media strategy was to build "a culture where staff routinely incorporate digital tools and media into all aspects of their work" (DFAT 2016, p. 7). DFAT provided its own understanding of the term "digital diplomacy which they defined as "the use of social media for diplomatic purposes [...] to engage in information sharing, public diplomacy, international negotiations and crisis management" (3). The strategy explicitly mentioned the significance of listening to domestic publics for gaining "domestic perspectives on what we're doing" (6). In this way, DFAT recognised that social media platforms were not only a tool for promoting Australian government policy but also for "creat[ing] and implement[ing] it" (3).

DFAT identified five principal components of its digital strategy: equip, listen, explain, engage and influence. According to DFAT, equipping diplomats meant providing both resources (for example, a centralised social media content library) and skills (mentoring and specialist recruitment) that could lead to confident use of social media by staff (11-13).

Another component of the strategy was listening, whichaccording to DFAT - would "add to our understanding of the world in which we work" (14). The strategy indicated how listening might be implemented in the practice of social media analytics:

Parliamentary and Media Branch will manage a range of high-level web and social media reporting and analytics tools that will identify influential groups and conversations, track sentiment towards Australian policy, measure the department's global social reach and enable centralised reporting on the progress of major campaigns (14-15).

Although this understanding of listening was limited by a focus on metrics such as content views and number of clicks, the strategy at least signalled an openness to hearing what online foreign publics had to say.

Another of the priorities highlighted in the strategy - and significant for this analysis - was to "generate engagement". According to DFAT's digital media strategy, engagement was a way to "strengthen and extend Australia's relationships through digital diplomacy, networking and by taking part in online discussions" (DFAT 2016, p. 19). The DFAT's understanding of engagement as "taking part in online discussions" was a clear sign of digital technologies being recognised as communication enablers-using platforms to build relationships with a variety of actors online. This, as I describe in the section below, is in stark contrast to the Cyber Engagement strategy that followed just a year later.

\section{From "digital" engagement to "international cyber engagement"}

In 2017, the DFAT published another important policy document entitled the Foreign Policy White Paper (Australian Government 2017a). Articulating a vision for Australian foreign policy, the DFAT consulted with experts and civil society by releasing a call for public submissions, some of which were incorporated in the final document.

In the White Paper, digital engagement was still framed as a means of supporting "a more open and consultative form of government, one in which governments both communicate their own messages and listen to diverse views". However, an initial transition in the terminology is evident here. While the digital strategy was about mainly "public diplomacy", the White Paper emphasised a renewed Australian focus on soft power and "Australia's ability to persuade and influence others" (Australian Government 2017a, pp. 107-115). This reflects an agent-centric framing of Australian international engagement compared to the Digital Media Strategy. The emphasis in the document is on strengthening the Australian international influence.

In a globalised and contested world, a systematic and sophisticated approach to soft power is in our national interest. To maintain our strengths in this area, and to ensure our capabilities and areas of focus keep pace with changes in technology, the Government will conduct a review to ensure we continue to build soft power and exercise influence effectively (Australian Government 2017a, 107).

The focus, therefore, was no longer on nurturing relationships but rather on exercising influence. The change in the terminology used by the DFAT is not accidental sincein contrast with the previous strategies-the White Paper does not mention public diplomacy at all. The focus is rather on soft power with the practical commitment of creating a stronger national brand. As Byrne (2017) points out in her analysis of the White Paper, this is "a formula that doesn't necessarily foster strong relationships, build trust or reflect credibility".

This shift in terminology becomes particularly evident in the document titled Australia's International Cyber Engagement Strategy (Australian Government 2017b) published in the same year as the White Paper. The latest development of DFAT's digital strategy marks the completion of the shift in the Australian approach to digital technologies. The new 
strategy replaces the previous focus on digital communication platforms as a means for international dialogic engagement with a new understanding of "cyberspace" mostly as infrastructure of highly strategic importance. This reinterpretation of the digital results in additional emphasis on issues such as digital trade, cybersecurity and internet governance.

The novelty is that this strategy seems to focus more on the challenges of "cyberspace" in a competitive international environment and the consequent need to "deter, mitigate and attribute malicious cyber activity by criminals, state actors and their proxies, including those that seek to interfere in the internal democratic processes of states" (5-6). This is certainly a reaction to those new forms of propaganda and cyberespionage mentioned above.

Developments in cyberspace have created a new arena in which states can exert influence. The increasingly complex nature of the international landscape means that more and more actors now pursue strategic goals in the digital domain; some challenging the international rules-based order in the process. Australia is committed to a peaceful and stable cyberspace. We will cooperate with international partners to deter and respond to malicious cyber activity that endangers international peace, security and stability. Reaffirming the application of international law to cyberspace, adhering to norms of responsible behaviour in cyberspace and implementing confidence-building measures will shape cyberspace as a landscape for international cooperation and mutual benefit (11).

This reinterpretation of cyberspace as an "arena" in which some national actors "challenge the international rules-based order" reveals a reinterpretation of the internet's possibilities. Digital technologies are no longer considered as communication planforms where relationships can be built and publics can be listened to. As a middle power, Australia's cultivation of international partnerships among states is reinterpreted as a means to protect Australia against enemies in cyberspace. This is emphasised even further in the DFAT's website profile of the inaugural Australian Ambassador for Cyber Affairs, Tobias Feakin, whose mandate is "to advance and protect Australia's national security, foreign policy, economic and trade, and development interests in the internet and in cyberspace" (DFAT n.d.).

Finally, recent policy documents published by the Australian Home Affairs Department also indicate that the Australian government is placing less importance on public diplomacy in the digital realm and seems to imply a reversion to more defensive forms of international engagement and digital listening focused on surveillance or surreptitious listening. While the public diplomacy (2014-2016) and the digital media (2016-2018) strategies are still waiting for much-needed updates, the Australian government has published two editions of Australia's Cyber Security Strategy in 2016 and in 2020. The latest edition, in particular, emphasises even further the need to put in place measures that aim to create "a more secure online world for Australians". This is in light of the increasing reliance on digital infrastructures for "governments, businesses, and the community" due to the Covid-19 pandemic (Australian Department of Home Affairs 2020, p. 7). References to "cyber threats" from "well-equipped and persistent state-sponsored actors [...] targeting critical infrastructure and stealing our intellectual property" are also mentioned in the Strategy's foreword by the Australian Minister of Home Affairs, Peter Dutton. ${ }^{6}$

\section{The institutionalisation of fear in the Australian foreign policy}

The DFAT's good intentions with the 2016 Digital Strategy seem to have been abandoned by new and pressing cybersecurity concerns. The DFAT's Digital Strategy was an important step towards enhancing Australian diplomats' digital skills. It was a response consistent with what the literature on public diplomacy has highlighted as important: creating opportunities for two-way communication online, taking advantage of the interactive nature of the platforms, and social media listening. The strategy was published before the concerns described above emerged around the use of the internet and before the Australian government's fear towards cyberattacks started to grow. In response to this fear, Australian policy and strategy saw a shift in the interpretation of the internet, now seen as strategic infrastructure that requires defending as well as coalition-building with those countries that believe in democratic values. This has consequences both for the way resources are allocated and on the communication posture adopted by the nation state.

What emerges from the analysis is the ongoing tension between soft and hard power, empathy and fear. This tension becomes particularly evident for middle powers such as Australia, since it is central for them to create partnerships and nourish influence in the world stage (Byrne 2020) while also putting into place measure to protect themselves. Diplomatic and public diplomacy approaches are typically sought when empathy is the driving force, but they are also a pragmatic way to project influence for middle powers. However, they are outbalanced when fear of perceived threats leads to the militarisation of cyber practices. As Crawford (2014, p. 547) warns, "where empathy is low and societies may be locked

\footnotetext{
${ }^{6}$ Commentaries seem to agree that this refers China since the growing tensions between the two countries (e.g. Probyn and Dziedzic 2020).
} 
in cycles of antipathy and aggression, fear and opportunities to increase it are institutionalized in military budgets, arms race dynamics, and cross-border skirmishes". States' responses to the increasing fear of threats emerging from the internet may be legitimate, but the analysis of Australian case indicates that such fear can result in neglecting longterm relational goals. Engagement, once intended as a way to "strengthen and extend Australia's relationships through digital diplomacy, networking and by taking part in online discussions" (DFAT 2016, p. 19) is now reframed as an agent-centric governmental engagement with cybersecurity issues. Listening, one of the foundational activities in public diplomacy which was intended as a communication act in its own right (refer to Di Martino 2020a, Cull 2019), risks being translated into more defensive and militarised approaches, such as spying or, to use the Australian government's terminology, "detecting" in order to "deter" threats.

Although many of the consequences of this policy shift will be seen in the actualisation of these strategies, the recent Australian (re)framing of the challenges brought about by the internet tends to preclude or limit the possibilities for listening, dialogic engagement and two-way forms of communication articulated in the previous public diplomacy and digital media strategies.

\section{Conclusion}

Although social media platforms have become mainstream in diplomacy, controversial uses of those platforms have created apprehension in governmental circles. At the beginning of this article, I explored the scholarly literature surrounding public diplomacy and social media. Six key terms have emerged with different degree of success: the new public diplomacy, digital diplomacy, cyber diplomacy, the dark side of diplomacy, new forms of propaganda and information warfare. The chronological description of these terms indicates increasing concerns about how social media might be used for hostile operations by national and non-national actors. Such evolution in the terminology signals a growing shift from the possibilities to the risks related to the use of the internet in international relations.

This change is also reflected in foreign policy strategies. I expand on Crawford's work by applying her concept of the institutionalisation of fear and empathy to the study of emotions in foreign policy. This analytical framework supports my subsequent analysis of the shift in focus in relation to Australian foreign policy. I argue that, although emotions in international relations cannot be "seen", they are one of the important drivers of a country's foreign policy. In particular, emotional perceptions of the environment in which nation states operate leave traces in foreign policy documents. These traces can be used to study how contrasting emotions of fear or empathy inform and shape a country's foreign policy.

This approach contributes to the discussion around emotions in international relations and policy making. It also provides an analytical tool that can be replicated in future studies that aim to study how emotions play a role in foreign policy evolution. This is particularly relevant in a world in which international tensions are increasing and more emphasis seems to be placed on the necessity to deter threats in cyberspace. Indeed, what emerges in this analysis is that when fear dominates policy discourse, resources and terminology shift towards military approaches. This is at the expense of diplomacy in general and public diplomacy in particular as can be seen in the case of Australia's evolving approach to digital technologies.

Moving the discussion to the academic study of public diplomacy, it emerges that the more belligerent international environment that we are witnessing lately seems to highlight the difficulty of getting the balance right between soft and hard power. At the same time, the national interest-which evolves and changes due to political shifts and contextual elements-is often at odds with the definition of public diplomacy engagement as mutual understanding and influence. Brown (2013) identified these tensions when he posed the foundational question as this: is public diplomacy an instrument of diplomacy and foreign policy or an opportunity for changing international relations and therefore the status quo?

In such a complex and networked communication environment, working to change the status quo by creating opportunities for international dialogue represents an occasion to enhance credibility and legitimacy for the nation state in the long term. In other words, public diplomacy can effectively serve foreign policy and strategic interests only if its transformative dimension is understood as a condition sine qua non for the advancement and legitimisation of a state's foreign policy. ${ }^{7}$ Effective public diplomacy requires constant attention to relation building and long-term goals without being undermined because of contextual challenges or threats. This seems particularly relevant for middle powers such as Australia.

Acknowledgements The author would like to sincerely thank the anonymous reviewers whose comments and suggestions helped improve and clarify this manuscript.

\section{Declarations}

Conflict of interest The corresponding author states that there is no conflict of interest.

\footnotetext{
${ }^{7}$ Similar remarks are made by Ang, Isar, and Mar (2015) in relation to cultural diplomacy.
} 


\section{References}

Ang, Ien, Yudhishthir Raj Isar, and Phillip Mar. 2015. Cultural Diplomacy: Beyond the National Interest? International Journal of Cultural Policy 21 (4): 365-381.

Australian Department of Home Affairs. 2020. Australia's Cyber Security Strategy. edited by Home Affairs. Canberra.

Australian Government. 2017a. 2017 Foreign Policy White Paper. Canberra: Australian Government.

Australian Government. 2017b. Australia's International Cyber Engagement Strategy. edited by Department of Foreign Affairs and Trade. Canberra.

Australian Senate. 2007. Australia's Public Diplomacy: Building Our Image. edited by Defence and Trade Senate Standing Commitee on Foreign Affairs. Canberra: Australian Senate.

Bacchi, Carol. 2009. Analysing policy: Pearson Higher Education AU.

Baines, Paul, Nicholas O'Shaughnessy, and Nancy Snow, eds. 2019. The SAGE Handbook of Propaganda. New York: Sage Publications.

Barash, Vlad, John Kelly, Bence Kollanyi, Lisa-Maria. Neudert, and Philip N. Howard. 2018. Polarization, Partisanship and Junk News Consumption over Social Media in the US. Data Memo 6 (02): 2018.

Barton, Chris. 2012. "Twitter diplomacy." NZ Herald, 24.08.2012. Accessed 15.03.2017. http://www.nzherald.co.nz/business/news/ article.cfm?c_id=3\&objectid=10828967.

Bjola, Corneliu. 2015. "Introduction: Making Sense of Digital Diplomacy." In Digital Diplomacy: Theory and Practice. Milton Park, Abingdon, Oxon ; New York: Routledge, 2015.

Bjola, Corneliu. 2016. Digital Diplomacy-The State of the Art. Global Affairs. https://doi.org/10.1080/23340460.2016.1239372.

Bjola, Corneliu, and Marcus Holmes. 2015. Digital Diplomacy: Theory and Practice. Milton Park: Abingdon.

Bjola, Corneliu, and James Pamment. 2016. Digital Containment: Revisiting Containment Strategy in the Digital Age. Global Affairs 2 (2): 131-142.

Bjola, Corneliu, and James Pamment, eds. 2018. Countering Online Propaganda and Extremism: The Dark Side of Digital Diplomacy. Edited by Corneliu Bjola and Markus Kornprobst, Routledge New Diplomacy Studies. New York: Routledge.

Bradshaw, Samantha, and Philip N Howard. 2018. Challenging Truth and Trust: A Global Inventory of Organized Social Media Manipulation. In The Computational Propaganda Project.

Brown, Robin. 2013. "Post ISA Thoughts." Public Diplomacy, Networks and Influence, 12.04.2013. https://pdnetworks.wordpress. com/2013/04/12/post-isa-thoughts/.

Brown, S.J., and M.S. Studemeister. 2001. Virtual Diplomacy: Rethinking Foreign Policy Practice in the Information Age. Information \& Security 7 (2001): 28-44.

Byrne, Caitlin. 2017. "Charting Australia's Diplomatic Future." Australian Outlook, 27.11.2017. http://www.internationalaffairs.org. au/australianoutlook/australias-diplomatic-future/.

Byrne, Caitlin. 2020. Truth, Lies and Diplomacy: Fostering Co-operation in a Fractured World. Griffith Review 67: 177-185.

Cave, Danielle. 2015a. "DFAT \& Digital Diplomacy: In Denial and in Need of Review." The Interpreter, 1.10.2015. https:// www.lowyinstitute.org/the-inter preter/dfat-digital-diplo macy-denial-and-need-review.

Cave, Danielle. 2015b. "Global Diplomacy has Gone Digital and Australia has been Left Behind." The Age, 22.09.2015. https:// www.theage.com.au/opinion/global-diplomacy-has-gone-digit al-and-australia-has-been-left-behind-20150922-gjs6tg.html.

Chitty, Naren. 2008. Australian Public Diplomacy. In Routledge Handbook of Public Diplomacy, ed. Nancy Snow and Philip M. Taylor, 314-323. London: Routledge.
Clinton, Hilary. 2010. "Remarks on Internet Freedom." Accessed 21.01.2010. www.state.gov/secretary/rm/2010/01/135519.htm.

Crawford, Neta C. 2014. Institutionalizing Passion in World Politics: Fear and Empathy. International Theory 6 (3): 535-557. https:// doi.org/10.1017/S1752971914000256.

Cull, Nicholas J. 2011. WikiLeaks, Public Diplomacy 2.0 and the State of Digital Public Diplomacy. Place Branding and Public Diplomacy 7 (1): 1-8.

Cull, Nicholas J. 2019. Public Diplomacy: Foundations for Global Engagement in the Digital Age. Cambridge: Polity Press.

DFAT. 2014. Public Diplomacy Strategy 2014-16. edited by Public Diplomacy branch. Canberra: DFAT.

DFAT. 2016. Digital Media Strategy 2016-18. Canberra: DFAT.

DFAT. n.d. "Australian Ambassador for Cyber Affairs." Australian Department of Foreign Affairs and Trade. https://www.dfat.gov. au/about-us/our-people/homs/Pages/ambassador-for-cyber-affai rs.

Di Martino, Luigi. 2020a. Conceptualising Public Diplomacy Listening on Social Media. Place Branding and Public Diplomacy 16 (2): 131-142. https://doi.org/10.1057/s41254-019-00135-5.

Di Martino, Luigi. 2020b. "The Spectrum of Listening." In Routledge Handbook of Public Diplomacy, edited by Nancy Snow and Nicholas J. Cull. New York: Routledge.

Dizard, Wilson. 2001. Digital Diplomacy: US Foreign Policy in the Information Age. Westport, Connecticut; London, UK: Praeger.

Duncombe, Constance. 2019. Digital Diplomacy: Emotion and Identity in the Public Realm. The Hague Journal of Diplomacy 2019 (1-2): 102-116. https://doi.org/10.1163/1871191X-14101016.

Erbschloe, Michael. 2017. Social Media Warfare: Equal Weapons For All. Boca Raton, FL: CRC/Taylor \& Francis.

Fisher, Ali. 2013. Collaborative Public Diplomacy: How Transnational Networks Influenced American Studies in Europe. New York, NY: Palgrave Macmillan.

Fletcher, Tom. 2016. The Future FCO Report. London: British Foreign and Commonwealth Office.

Fong, Ben. 2010. "“Didn't You Get the Memo?": Changing Discourses of Diplomacy in the Age of Information." International Affairs Review XVIII (3, Winter 2010).

Forenstein, Gregory. 2011. "Hillary Clinton's Senior Tech Advisor Talks 'Radical' Global Citizenship." Fast Company, 4.04.2011. Accessed 15.03.2017. https://www.fastcompany.com/1744389/ hillary-clintons-senior-tech-advisor-talks-radicalglobal-citiz enship.

Gilboa, Eytan. 1998. Media Diplomacy: Conceptual Divergence and Applications. The Harvard International Journal of Press/Politics 3 (3): 56-75. https://doi.org/10.1177/1081180X98003003005.

Glassman, James K. 2008. Public Diplomacy 2.0: A New Approach to Global Engagement. Washington, DC: Archive for the U.S. Department of State.

Graffy, Colleen. 2009. "The Rise of Public Diplomacy 2.0." The Journal of International Security Affairs 17.

Graham, Sarah Ellen. 2014. Emotion and Public Diplomacy: Dispositions in International Communications, Dialogue, and Persuasion. International Studies Review 16 (4): 522-539. https://doi.org/10. 1111/misr.12156.

Grant, Richard. 2004. The Democratisation of Diplomacy: Negotiating with the Internet. Edited by Dominic Kelly, Discussions Papers in Diplomacy. The Hague: Netherlands Institute of International Relations 'Clingendael'.

Greenwald, Glenn. 2013. "NSA Collecting Phone Records of Millions of Verizon Customers Daily." The Gurdian, 6.06.2013. https:// www.theguardian.com/world/2013/jun/06/nsa-phone-recordsverizon-court-order.

Grimme, Christian, Mike Preuss, Lena Adam, and Heike Trautmann. 2017. Social Bots: Human-Like by Means of Human Control? Big Data 5 (4): 279-293. 
Heine, Jorge, and Joseph F Turcotte. 2012. "Tweeting as Statecraft: How, Against All Odds, Twitter Is Changing the World's Second Oldest Profession." Crossroads: The Macedonian Foreign Policy Journal 3 (2).

Hocking, Brian. 2008. Reconfiguring Public Diplomacy from Competition to Collaboration. In Engagement: Public Diplomacy in a Globalised World, ed. Jolyon Welsh and Daniel Fearn, 63-75. London: Foreign and Commonwealth Office.

Hocking, Brian, and Jan Melissen. 2015. Diplomacy in the Digital Age. The Hague: Clingendael, Netherlands Institute of International Relations.

Kurbalija, Jovan. 2013. Ten parallels between the telegraph and the Internet in international politics. Diplo Blog. https://www.diplo macy.edu/blog/ten-parallels-between-telegraph-and-internet-inter national-politics.

Landau, S. 2014. Highlights from Making Sense of Snowden, Part II: What's Significant in the NSA Revelations. IEEE Security \& Privacy 12 (1): 62-64. https://doi.org/10.1109/MSP.2013.161.

Lichtenstein, Jesse. 2010. "Digital Diplomacy." The New York Times Magazine, 16.07.2010. Accessed 25.03.2017. http://www.nytim es.com/2010/07/18/magazine/18web2-0-t.html?src=tptw\&pagew anted $=$ all.

Manor, Ilan. 2016. Are We There Yet: Have MFAs Realized the Potential of Digital Diplomacy? Brill Research Perspectives in Diplomacy and Foreign Policy 1 (2): 1-110.

Melissen, Jan. 2005. The New Public Diplomacy: Between Theory and Practice. In The New Public Diplomacy: Soft Power in International Relations, ed. Jan Melissen, 3-27. London: Palgrave Macmillan.

Melissen, Jan. 2011. Beyond the New Public Diplomacy. The Hague: Clingendael, Netherlands Institute of International Relations.

Morozov, Evgeny. 2011. The Net Delusion: The Dark Side of Internet Freedom. London: Allen Lane.

Nye, Joseph S. 2004. Soft Power: The Means to Success in World Politics. New York: Public Affairs.

Pamment, James, Howard Nothhaft, and Alicia Fjällhed. 2018. Countering Information Influence Activities: A Handbook for Communicators. Stockholm: Department of Strategic Communication.

Pariser, Eli. 2011. The Filter Bubble: What the Internet Is Hiding from You. New York: Penguin Press.

Potter, Evans H. 2002. Cyber-Diplomacy: Managing Foreign Policy in the Twenty-First Century. Montreal: McGill-Queen's University Press.

Probyn, Andrew, and Stephen Dziedzic. 2020. "Scott Morrison's 'Urgent' Hacking Warning Shot Shows Australia Won't Shy Away from China's Cyber Attacks." ABC News. https://www.abc.net. au/news/2020-06-20/why-australia-acted-on-china-hacking-cyberattack-scott-morrison/12376700.

Richter, Hannes R. 2016. "Web 2.0 and Public Diplomacy." In Cyberspaces and Global Affairs, edited by Sean S. Costigan and Jake Perry, 105-118. Farnham: Taylor and Francis.

Riordan, Shaun. 2016a. "Cyber Diplomacy vs. Digital Diplomacy: A Terminological Distinction." CPD Blog. https://www.uscpublicd iplomacy.org/blog/cyber-diplomacy-vs-digital-diplomacy-termi nological-distinction.

Riordan, Shaun. 2016b. "Digital Diplomacy 2.0: Beyond the Social Media Obsession." CPD Blog, 25.04.2016. http://uscpublicd iplomacy.org/blog/digital-diplomacy-20-beyond-social-mediaobsession.

Riordan, Shaun. 2019. Cyberdiplomacy: Managing Security and Governance Online. Cambridge: Polity Press.

Sandre, Andreas. 2015. Digital Diplomacy: Conversations on Innovation in Foreign Policy. Lanham: Rowman \& Littlefield.

Seib, Philip. 2012. Real-Time Diplomacy: Politics and Power in the Social Media Era: Palgrave Macmillan.

Seib, Philip. 2016. The Future of Diplomacy. Newark, NJ: Wiley.

Smith, Gordon S. 2010. Reinventing Diplomacy: A Virtual Necessity: US Institute of Peace.

Solon, Olivia. 2016. "Facebook's Failure: Did Fake News and Polarized Politics Get Trump Elected?" The Guardian, 11.11.2016. Accessed 12.01.2017. https://www.theguardian.com/technology/ 2016/nov/10/facebook-fake-news-election-conspiracy-theories.

Sotiriu, Sabrina. 2015. "Digital Diplomacy: Between Promises and Reality." In Digital Diplomacy: Theory and Practice, edited by Corneliu Bjola, Marcus Holmes and Corporation Ebooks, 33-51. Abingdon, Oxon ; New York: Routledge.

Trent, Deborah L. 2016. "App or No App, Public Diplomacy is Still All About Relationships." CPD Blog, 12.02.2016. http://uscpu blicdiplomacy.org/blog/app-or-no-app-public-diplomacy-still-allabout-relationships.

Tufekci, Zeynep. 2018. It's the (Democracy-Poisoning) Golden Age of Free Speech. Wired 16 (01): 2018.

U.S. Department of State. n.d. "21st Century Statecraft [Archived website 2009-17]." U.S. Department of State. https://2009-2017.state. gov/statecraft/overview/index.htm.

Westcott, Nicholas. 2008. "Digital diplomacy: The Impact of the Internet on International Relations."

Zaharna, Rhonda S. 2010. Battles to Bridges: US Strategic Communication and Public Diplomacy after 9/11. Basingstoke: Palgrave Macmillan.

Publisher's Note Springer Nature remains neutral with regard to jurisdictional claims in published maps and institutional affiliations.

Luigi Di Martino is an Institute Associate at the Institute for Culture and Society at Western Sydney University. His research interests include public diplomacy, social media engagement and digital methods. Recent works have focused on theories and practices of social media listening in public diplomacy and the assessment of social media engagement in international communication. 